\title{
A new process for desalination and electrodeionization of water by means of electrostatic shielding zones - ionic current sinks.
}

\author{
K. Dermentzis*,1 ${ }^{*}$ D. Papadopoulou ${ }^{1}$, A. Christoforidis ${ }^{2}$ and A. Dermentzi ${ }^{3}$ \\ ${ }^{1}$ Technological Education Institute (TEI) of Kavala, Department of Science, Laboratory of Chemical Technology and Electrochemistry, \\ ${ }^{2}$ Department of Petroleum \& Natural Gas Technology, Laboratory of Environmental Protection, 65404 Agios Loucas, Kavala, Hellas, \\ ${ }^{3} 1^{\text {st }}$ Lyceum of Kavala, 65302 Kavala, Hellas \\ Received 15 December 2009; Revised 27 April 2009; Accepted 4 May 2009
}

\begin{abstract}
We constructed electrostatic shielding zones made of electrode graphite powder and used them as a new type of ionic and electronic current sinks. Because of the local elimination of the applied electric field, voltage and current within the current sinks, ions are led inside them and accumulate there. The sinks become ion concentrating compartments whereas the adjacent compartments become ion depleting compartments. The proposed electrodeionization process uses no permselective ion exchange membranes. We implemented it in electrodialysis desalination of a synthetic brackish $0.03 \mathrm{M} \mathrm{NaCl}$ solution and obtained potable water with a $\mathrm{NaCl}$ concentration $<500 \mathrm{mg} \mathrm{L}^{-1}$. Furthermore, we performed electrodialysis of $0.002 \mathrm{M} \mathrm{NiSO}_{4}$ and electrodeionization of $0.001 \mathrm{M} \mathrm{NiSO}_{4}$ solutions with simultaneous electrochemical regeneration of the used ion exchange resin beds. By the continuous mode of electrodeionization of the $0.001 \mathrm{M} \mathrm{NiSO}_{4}$ solution we obtained pure water with a $\mathrm{Ni}^{2+}$ ion concentration of less than $0.5 \mathrm{mg} \mathrm{L}^{-1}$ at a flow rate of $2.3 \times 10^{-4} \mathrm{~L} \mathrm{~s}^{-1}$ diluate stream
\end{abstract}

Keywords: Desalination, nickel removal, membrane-less electrodialysis, faraday cage, water reuse.

\section{Introduction}

Intensive industrialization and the associated water pollution compose a gradually increasing threat of fresh water shortage in many areas of the world. Purification of used, polluted and contaminated water or desalination of brackish and seawater have recently won an increased technological interest which apparently will become more urgent in the not distant future.

Deionization (DI) is the removal of ions and ionizable species from water or organic liquids and may be achieved by various techniques, such as Ion Exchange (IE), Reverse Osmosis (RO), Distillation and Electrodeionization (EDI). EDI uses electrically active media and an electrical potential to cause ion transport and may be operated batch wise, or continuously.

Continuous processes such as Electrodialysis [1,2], Electrodialysis Reversal [3], and Filled Cell Electrodialysis or otherwise called Continuous Electrodeionization [4,5] comprise alternating permselective cation exchange membranes and anion exchange membranes, which under the influence of the electric field allow only cations or only anions respectively to permeate their mass and simultaneously retain coions so that diluate and concentrate compartments are created and deionization occurs.

\footnotetext{
*E-mail address: demerz@otenet.gr

ISSN: 1791-2377 @ 2009 Kavala Institute of Technology. All rights reserved.
}

Electrodialysis has been successfully performed over the last decades mainly in the production of potable water from brackish or seawater [6], regeneration of ion exchange resins $[4,5]$ and production of pure or ultrapure water, demineralization and deacidification in food or pharmaceutical processing [7], purification of radioactive waste water in nuclear power plants [8] and recovery of water and valuable metals from industrial effluents [9-13].

Electrodialysis is an ecologically expedient and economically profitable method of water demineralization. However, the efficiency of the method is limited by the so called limiting current density [14-19] which is the state where the electrolyte concentration at the membranesolution interface reaches values much less than in the bulk solution. In this state the salt ion current reaches its saturation and does not grow with voltage increase. The observed current increase in the overlimiting region is attributed mainly to the partial currents of $\mathrm{H}^{+}$and $\mathrm{OH}^{-}$-ions due to water dissociation. As a result, the electrolyser capacity is restricted, desalting can not be enhanced and only unproductive energy consumption occurs. Because of the membrane selectivity, only counterions can enter the membrane while coions are repelled. This phenomenon leads to a decrease in electrolyte concentration near the membrane side and causes the known undesirable membrane associated limitations, such as depleted boundary layer, concentration polarization, limiting current density and water dissociation. Many improvements have been made by different researchers for enhancement and intensification of electrodialysis [20-23]. Batch processes such as Capacitive Deionization [24-26] are collection/discharge processes which rely on the formation of double-layer supercapacitor at the solution/electrode interface and need electrodes with large specific areas such as activated carbon aerogels. Capacitive deionization is an energy efficient method of water deionization but the needed carbon aerogel electrodes are very costly and have a relatively low salt sorption 
capacity. Furthermore, because capacitive deionization is a batch process and is operated at low voltage (1.2 -1.7 V), it needs a very large number of stacked electrode pairs to perform a particular task which by far increases its capital costs and therefore prevents this technology from being competitive to other desalination technologies. In addition, in classical capacitive deionization cells no separate diluate and concentrate compartments exist, the produced deionized water during the electrode charging step is first removed, because during the electrode discharging (regeneration step) the captured ions are released in the same space producing a concentrate stream, which of course must also be removed. Then the electrodes must be rinsed with deionized water and only after all this procedure the next electrode charging (deionization step) can start. Furthermore, dependent on feed water concentration, a multi-stage treatment is required i.e. the treated water is collected and subsequently used as feed water for the next experiment simulating a successive multistage process.

Current research suggests a promising future for capacitive deionization and has been focusing on developing low cost electrodes with greater micro- or nano-porosity and larger specific surface area and thereby higher salt sorption capacity in order to reduce the capital costs [27-30].

New nanoporous carbon aerogel electrodes [28,30-32], carbon nanotubes and nanofibers [33-36], or activated nanostructured carbon cloths [29,37-39] have been recently developed with increased specific surface area which reduce the number of the electrode charge/discharge cycles and therefore improve significantly the desalting rate and the efficiency of the capacitive deionization process.

The present paper offers a new alternative way of electrochemical purification of water by means of electrostatic shielding zones (ESZs) and ionic current sinks (ICSs).

The proposed new electrodeionization process differs from classical electrodialysis-continuous electrodeionization processes in that it does not use any permselective ion exchange membranes and therefore it does not exhibit the already mentioned membrane associated limitations. It also differs from classical batch wise operated capacitive deionization in that it is a continuous process i.e. diluate and concentrate are received from separate and unchanged compartments without any removal of diluate and concentrate or any down time for electrode saturation, regeneration and rinsing steps.

Current sinks and sources are local currents from a location where they can be detected into a location they can not be detected (current sink) or vice versa (current source). Current sinks and sources have particular relevance in current across biological membranes (neurobiology) and have proved to be valuable in the study of brain fuction [40]. Furthermore, current sinks are used in several electronic applications $[41,42]$.

However, all known current sinks are related to electronic current sinks (ECSs). Our search throughout literature has not resulted in any other paper except for our previous works [43-45] dealing with ICSs. We created ICSs through electrostatic shielding by employing electronically and ionically conducting media e.g. graphite powder and used them as ion concentrating compartments in form of ESZs.

\section{Experimental}

We used platinized titanium grids as end-electrodes in all our experiments.

The intermediate electrodes ICSs must be electronically and ionically conducting. They are either two parallel shortcircuited stainless steel perforated plates or platinized titanium grids (fig. 1a,b,c) or packed beds of graphite powder (Merck, particle size $<50 \mu \mathrm{m}$, electrical conductivity $2 \times 10^{4} \mathrm{~S} \mathrm{~m}^{-2}$ ) or electrode graphite powder (fig. 2a,b and fig. 3 ) which is used as anode by the electrolytic production of aluminium (Aluminium of Greece, particle size $<1 \mathrm{~mm}$, electrical conductivity $3.3 \times 10^{4} \mathrm{~S} \mathrm{~m}^{-2}$ ). Anode graphite is preferable because of its better electrical and electrocatalytic properties. The ICS beds used for the electrodialysis experiments (fig.2a,b) are $5 \mathrm{~mm}$ thick each, while the ICS bed used for the filled cell electrodeionization (fig.3), is thicker $(10 \mathrm{~mm})$.
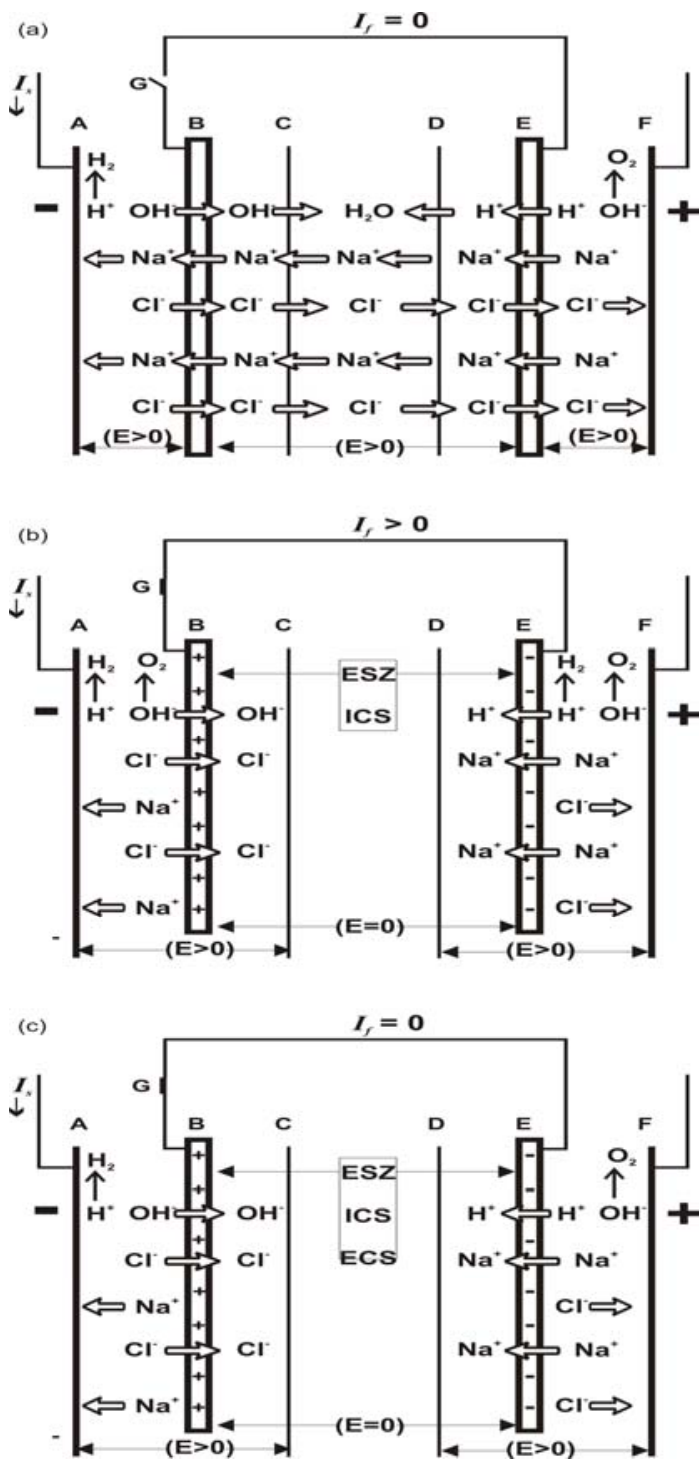

Fig. 1 (a) Electrolytic cell without ESZ-ICS. The intermediate electrodes B and E are disconnected, (b) the same cell with ESZ-ICS and charge transfer reactions at the connected $\mathrm{B}$ and $\mathrm{E}$. The potential difference $E_{B-E}$ between $B$ and $E$, before shorting is greater than the electrochemical decomposition potential of water $\mathrm{E}_{d}\left(\mathrm{E}_{\mathrm{B}-\mathrm{E}}>\mathrm{E}_{\mathrm{d}}, \mathrm{I}_{f}<\mathrm{I}_{\mathrm{s}}\right)$, (c) the same cell with ESZ-ICS-ECS without charge transfer reactions at $\mathrm{B}$ and $\mathrm{E}\left(\mathrm{E}_{B-E}<\mathrm{E}_{\mathrm{d}}, \mathrm{I}_{f}=0, \mathrm{I}_{\mathrm{s}}>0\right)$.

\subsection{Electrodes}



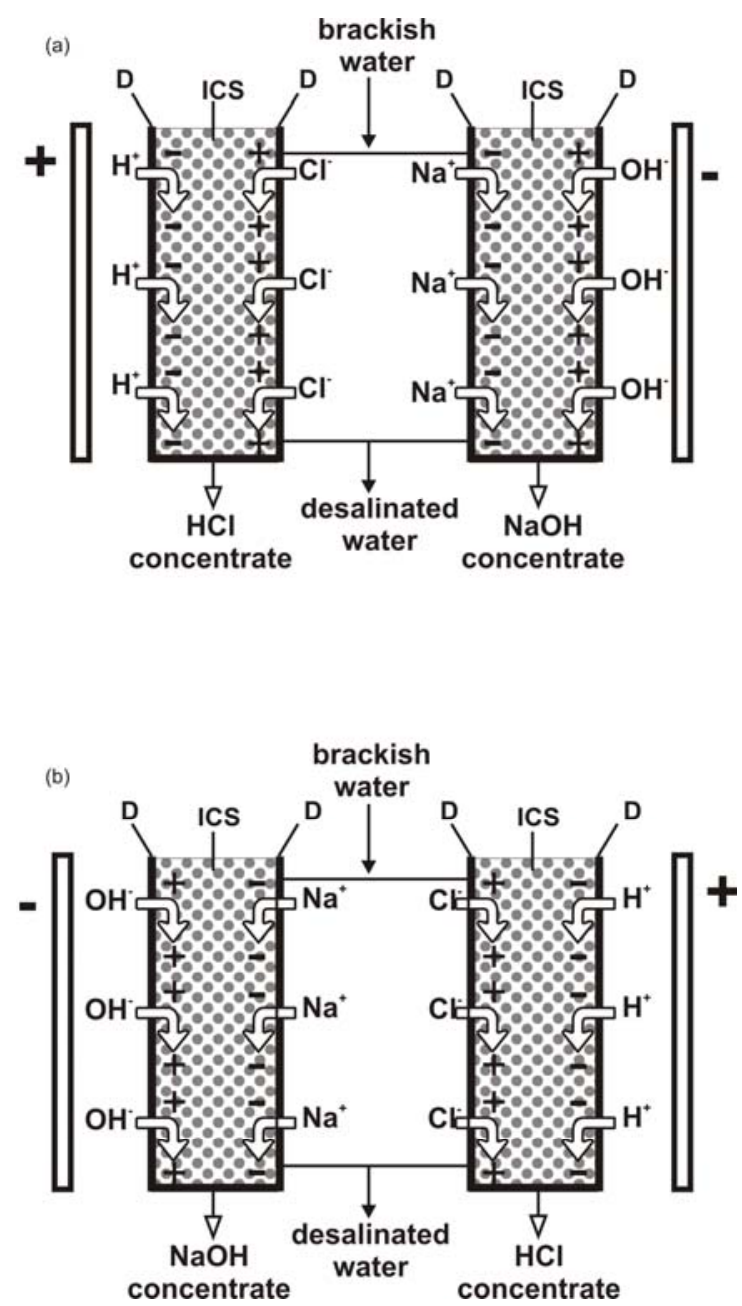

Fig. 2 (a) schematic diagram of an electrodialysis cell for electrostatic shielding desalination of brackish water with simultaneous splitting of $\mathrm{NaCl}$ and regeneration of $\mathrm{HCl}$ and $\mathrm{NaOH},(\mathrm{b})$ the same cell by polarity reversal

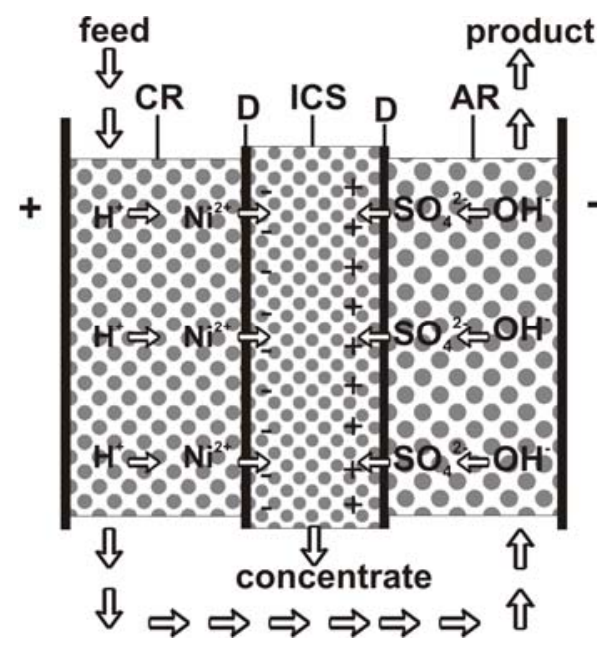

Fig. 3 Schematic diagram of an electrodeionization cell for removal of $\mathrm{Ni}^{2+}$ ions with simultaneous regeneration of ion exchange resin beds. The cell contains only one ICS and two separated ion exchange resin beds CR and AR placed in the anodic and cathodic compartment respectively.

\subsection{Diaphragms}

The cell compartments are separated from each other by $3 \mathrm{~mm}$ thick compact and water tight ion conducting ceramic diaphragms or cardboard sheets $\mathrm{D}$ which prevent intermixing of solutions without obstructing the migration of ions in the electric field. The diaphragms used for electrodialysis and electrodeionization (fig.2a,b and fig.3) should be ceramic, polymeric or cardboard sheets with low zeta potentials to avoid aimless transport of purified water into the ion sinks (ICSs).

\subsection{Cells}

We constructed a self-made electrolysis cell with a suitable electrode arrangement (fig.1a,b,c) to demonstrate the effect of electrostatic shielding and faraday cage and the formation of ESZ, ICS and ECS. All stainless steel perforated plate or platinized titanium grid electrodes $\mathrm{A}, \mathrm{B}, \mathrm{C}, \mathrm{D}, \mathrm{E}$ and $\mathrm{F}$ have the dimensions $5 \times 5 \times 0,1 \mathrm{~cm}$ and are placed in parallel. The distance between two successive electrodes is $1 \mathrm{~cm}$. The thicker indicated electrodes B and E are double stainless steel or platinized titanium grids in conduct to secure effective shielding. The electrodes are housed in a plastic electrolytic cell. The area of each electrode is equal to the vertical cross-section of the electrolytic cell. Potable water with a conductivity of $445 \mu \mathrm{S} \mathrm{cm}-1$ was used as electrolytic solution.

The self-made electrodialysis cell illustrated in fig.2 contains two ICSs serving as ion traps, one diluate compartment between them and two electrode compartments, all placed in parallel. Each compartment is $15 \mathrm{~cm}$ in length and $12 \mathrm{~cm}$ in width. The ICSs have a thickness of $5 \mathrm{~mm}$ and an effective area of $150 \mathrm{~cm}^{2}$ each. The area of each ICS is equal to the vertical cross-section of the electrolytic cell. All compartments are separated from each other by the diaphragms D. The distance between two successive ICSs and also between the ICS and the adjacent end-electrode is $5 \mathrm{~mm}$ and is determined by the ion conducting diaphragms and spacers.

The diaphragms are sealed so that the different compartments do not communicate hydraulically with each other but only electrically (ionically) through the electric field. Each ICS has a bipolar function and belongs simultaneously to two adjacent diluate compartments as in bipolar electrochemical double layer supercapacitors without the dense, water-tight electronically but non ionically conducting inner layer which separates the two charged porous outer layers [46].

The diaphragms D can be omitted in case porous sheets, such as conductive ceramics, porous carbon aerogel sheets, porous carbon papers or other porous composite electrodes are used which can function both, as intermediate electrodes and diaphragms as well.

The central diluate compartment as well as the two electrode compartments are filled with the feed solution, while the two concentrate compartments ICSs are only intermittently rinsed with the feed solution and are steadily let to drain. This pressure difference caused by the different water levels between the central diluate compartment and the concentrate compartments ICSs prevents diffusional leakage of ions from the more concentrated ICS-solution into the adjacent diluted one. Deionization in the diluate compartment can not be realized without keeping the water level inside the ICSs at lowest level. If the feed solution in the diluate compartment is soaked in a porous material, no 
pressure difference between the diluate and concentrate compartment exists. Deionization in the diluate compartment is realized without any pressure so long as the concentrate solution level is kept lowest by simply letting it to drain from the porous water permeable bottom of the ICS. Furthermore, the porous ionically and electronically conductive media of which the ISCs are made must cover uniformly all their space without allowing any ions to escape from the central diluate compartment to the electrode compartments or in the opposite direction without passing through their mass.

To complete physical absorption of salts into graphite powder the ICSs are rinsed with feed solution or other salt solution. For removal of impurities contained in graphite powder the cell should be filled with an acidic solution e.g. $2 \mathrm{mM} \mathrm{CaSO}_{4}+2 \mathrm{mM} \mathrm{H}_{2} \mathrm{SO}_{4}$ and put in operation for about 48 hours before any measurements are taken.

Graphite powder used as ICS material is chemically and thermally very stable but electrochemically quite stable, because it starts to corrode when its relatively narrow potential window is exceeded. Thinner ICSs are more stable and can operate at increased current densities. Platinized or ruthenized graphite and activated carbon powder, platin spongue or other dimensionally stable electrodes are stable and suitable even at higher fields but are more expensive.

The self-made electrodeionization cell shown in fig. 3 contains only one ICS. All cell compartments, anodic, cathodic and ICS are $10 \mathrm{~mm}$ thick.

\subsection{Apparatus}

Atomic Absorption Spectroscopy AAS (Perkin Elmer S100) was used to determine the $\mathrm{Ni}^{2+}$ ion concentrations in water. A power supply (PHYWE ) was used to maintain constant DC voltage. Voltage and current were measured by a multimeter (PHYWE ). Conductivities were measured by means of a conductometer (inoLab WTW). The temperature was held at $298 \pm 3 \mathrm{~K}$ during all experiments.

\subsection{Chemicals}

$\mathrm{NaCl}$ and $\mathrm{NiSO}_{4}$ were of analytical grade (Merck). The ion exchange resins used were strongly cation exchanger $\mathrm{H}^{+}$form (Amberlite IR-120, Merck,) with an ion exchange capacity of $1.7 \mathrm{mmol} \mathrm{ml}$ and strongly basic anion exchanger $\mathrm{OH}^{-}$-form (Merck) with an ion exchange capacity of $1.45 \mathrm{mmol} \mathrm{ml}^{-1}$.

\section{Results and discussion}

\subsection{ESZs, ICSs and ECSs}

It is known from electric field theory and Faraday cage [47] and our previous works $[44,45]$ that, when a conductor is placed inside an electric field, an opposite field is formed so that the original electric field in the interior of the conductor is canceled. The field intensity inside the conductor is zero and its whole space is electrostatically shielded independent on the external field intensity. Therefore, an abrupt potential jump is formed between the inside and the outside of the conductor. Since in an electrolytic or an electrodialysis cell ion migration is caused by the applied electric field, it will stop within an electronically and ionically conducting ICS of zero field, interposed between the anode and cathode.
The effect of electrostatic shielding and Faraday cage can be applied also to electric fields in electrolytic or electrodialytic cells and can be demonstrated with the following arrangement (fig.1a,b,c). Measurements of voltages, currents and field intensities inside and outside the ICSs i.e. with and without shielding are given in table1. As it is obvious, when a voltage is applied between the cathode A and the anode $\mathrm{F}$ a homogenous electric field with a constant field intensity is developed throughout the cell. Potential difference, current flow and field intensity are measured between the electrodes A-F, B-E, C-D, A-B and E-F (fig.1a). If, by means of a conducting wire and a switch (G), the electrodes B and E are electrically connected to each other (fig.1b,c), the whole space determined by them is electrically shielded constituting an ESZ and the former measured potential, current and field intensity values between the electrodes $\mathrm{C}$ and $\mathrm{D}$ almost disappear or fall abruptly. These values can reappear again only if the electrodes B and E are electrically disconnected (fig.1a). This occurs because the electrodes $\mathrm{C}$ and D lie inside the ESZ determined by the connected electrodes B and E. The ESZ becomes a kind of an electrochemical Faraday cage which is electrically "shielded" though current flows in the electrolytic cell.

Because of the homogenous electric field in fig.1a both, anions and cations permeate all porous or perforated intermediate electrodes and migrate in field direction throughout the cell. In fig. $1 \mathrm{~b}, \mathrm{c}$ because of the inhomogenous electric field ions migrate only in the left (cathodic) and the right (anodic) cell compartment. Ions can enter the middle compartment ESZ determined by the short-circuited electrodes B and E but due to the local absence of the electric field (driving force) their electromigration is stopped there. Ions can not leave this compartment and accumulate there. The ESZ becomes an ion concentrating compartment while the adjacent compartments become ion diluting compartments. The ESZ acts here as a "sink" for ions and ionic currents (ICS). The ionic current (real direction) is eliminated at the cathodically polarized side of the ICS (current sink) and appears again at its anodically polarized side (current source). Ions can move inside the ICS but only by diffusion and convection and not in field direction.

Fig.1b differs from fig.1c in the value of potential difference between the electrodes $\mathrm{B}$ and $\mathrm{E}$ before their shortcircuiting which is about 2 Volts. This critical potential value is higher than the Nerst potential for the electrochemical breakdown of water (1,23 Volt). However, intrinsic resistance of the electrodes permits an overvoltage and does not generate hydrogen and oxygen bubbles due to electrolysis at this voltage $[33,48,49]$. When the potential difference between $B$ and $E$ exceeds the value of 2 Volts ions not only enter the middle ICS compartment but simultaneously they can also be discharged at the electrodes $\mathrm{B}$ and $\mathrm{E}$ through electron transfer reactions. In this case a faraday current $\mathrm{I}_{f}$ due to electrolysis is observed between $\mathrm{B}$ and $\mathrm{E}$ (fig.1b). At lower potential difference ions can not be discharged at the electrodes $\mathrm{B}$ and E. No electrolysis and no faraday current is detected between them $\left(\mathrm{I}_{f}=0\right.$, fig. $\left.1 \mathrm{c}\right) . \mathrm{H}^{+}$ and $\mathrm{OH}^{-}$ions are discharged at the cathode and the anode respectively. The anions left over in the cathodic compartment and the cations left over in the anodic compartment permeate $\mathrm{B}$ and $\mathrm{E}$ respectively and accumulate inside the ICS determined by them (fig. 1c). In this way electroneutrality is maintained in all cell compartments.

The ion concentrating compartment ICS is never saturated with the accumulated ions. Because of the electric 
field its two connected sides become polarized and saturated with oppositely charged ions but at the same time they are discharged and release the same ions because of shorting. In fig. $1 \mathrm{~b}$ the ionic current disappears inside the ESZ-ICS and is partially converted to electronic current $\mathrm{I}_{f}$. In fig. $1 \mathrm{c}$ both, ionic and electronic current disappear completely inside the ESZ-ICS-ECS, though the circuit is closed and current flows through the cell $\left(\mathrm{I}_{f}=0, \mathrm{I}_{s}>0\right)$.

We can see in table 1, that the ICS (electronic conductor) does not need practically any potential to carry the current through its mass. By connecting (shorting) the electrodes B and $\mathrm{E}$ of the ICS the initial potential difference between them becomes zero, while the potential between the electrodes A-B and E-F and the current $\mathrm{I}_{\mathrm{S}}$ flowing the cell increase (table 1, fig.1a,b,c). The relatively to electrolytic solutions high electronically conducting ICS not only does not bring about any additional potential drop in the cell but, on the countrary, it helps the current $\mathrm{I}_{s}$ flowing the cell to increase by lowering the total resistance of the cell. Its initial potential difference between B-E is balanced between A-B and E-F. The ICS consumes no electrical energy $(\mathrm{E}=\mathrm{U} \cdot \mathrm{I}=$ $\mathrm{I}^{2} \cdot \mathrm{R}=0$, since $\mathrm{U}_{I C S}=0$ or $\mathrm{R}_{I C S}=0$ ). In multi-cell stacks where a series of concentrate compartments (ICSs) and diluate compartments alternate, the unit cell comprises one diluate compartment and one ICS. The electrical energy is consumed for electromigration of ions only in the diluate compartment which is energetically very favorable.

Up to now, no other work appeared in literature dealing with such ionic and electronic sinks. We can take advantage of these useful new findings and drive ions inside the ICSs, create ion concentrating and ion depleting compartments and perform in this way electrochemical purification of water and industrial effluents.

\subsection{Electrostatic shielding electrodialysis of a synthetic brackish NaCl solution}

The Middle East and Africa are currently experiencing serious shortages of potable water, while population growth and industrialization are making the problem more serious. In many coastal areas of Greece and other Mediterranean countries underground water suffers saline contamination due to intensive pumping for irrigation and the proximity to the sea and thus has become brackish. There are large reserves of brackish water to be used to solve these problems, if there was a way to cost-effectively desalinate them.

As $\mathrm{NaCl}$ is the main solute contained in brackish or seawater, we have treated a brackish 0.03M $\left(1755 \mathrm{mg} \mathrm{L}^{-1}\right)$ $\mathrm{NaCl}$ solution with the cell shown in fig. 2 and obtained fresh potable water which is under the recommended international standards $\left(500 \mathrm{mg} \mathrm{L}^{-1}\right)$. The electrodialytic process was conducted both, batch wise and continuously. For the batch wise operated process the $\mathrm{NaCl}$ containing solution was placed in the diluate compartments. $\mathrm{Na}^{+}$and $\mathrm{Cl}^{-}$ ions together with electroosmotically transported water molecules accumulate inside the ICSs as a concentrate which can be received from their water permeable bottoms. The process was carried out under constant voltage and decreasing current. Measurements were taken every four minutes and results are shown in table 2.
Table 2.

Electrostatic shielding desalination of a synthetic brackish $0.03 \mathrm{M}\left(1755 \mathrm{mg} \mathrm{L}^{-1}\right) \mathrm{NaCl}$ solution. (current density i $=1.82-1.00 \mathrm{~mA} \mathrm{~cm}^{-2}$, solution volume $\left.\mathrm{V}=75 \mathrm{ml}\right)$.

\begin{tabular}{rccccc}
\hline $\begin{array}{c}\text { Time } \\
(\mathrm{min} .)\end{array}$ & $\begin{array}{c}\text { Current } \\
(\mathrm{mA})\end{array}$ & $\begin{array}{c}\text { Conductiv } \\
\text { ity } \\
\left.(\mu \mathrm{S} \mathrm{cm})^{-1}\right)\end{array}$ & $\begin{array}{c}\text { Concentra } \\
\text { tion } \\
\mathrm{NaCl}^{-1}(\mathrm{mg} \\
\left.\mathrm{L}^{-1}\right)\end{array}$ & $\begin{array}{c}\text { Removal } \\
\mathrm{NaCl}(\%)\end{array}$ & $\mathrm{pH}$ \\
\hline 0 & 273 & 3317 & 1755 & - & 7.00 \\
4 & 248 & 2487 & 1309 & 25.4 & 7.21 \\
8 & 225 & 1808 & 937 & 46.6 & 7.33 \\
12 & 201 & 1313 & 660 & 62.4 & 7.45 \\
16 & 177 & 838 & 409 & 76.7 & 7.54 \\
20 & 163 & 678 & 326 & 81.4 & 7.66 \\
24 & 155 & 325 & 155 & 87.3 & 7.73 \\
28 & 150 & 249 & 118 & 91.2 & 7.81 \\
\hline
\end{tabular}

It must be mentioned that only $\mathrm{Na}^{+}$and $\mathrm{Cl}^{-}$ions existed in the feed solution to be purified. $\mathrm{pH}$ is a noise factor which does not change significantly in the central diluate compartment during operation of this electrodialysis setup (fig.2). Similar results about insignificant $\mathrm{pH}$ effect on the performance of classical membrane electrodialysis cells are referred in literature [50]. Since $\mathrm{pH}$ of diluate does not vary significantly conductivity measurements are adequate for investigation of $\mathrm{NaCl}$ concentrations in the treated solution. Of course, $\mathrm{pH}$ changes significantly in the cathodic and the anodic compartments (fig.2) due to corresponding hydrogen and oxygen evolution but these $\mathrm{pH}$ variations do not play any influential role on the performance of electrodialysis in the central diluate compartment. By operating the process under alternating polarity $\mathrm{pH}$ remains constant in all cell compartments.

It can be obtained from table 2 that the current, conductivity and concentration of the treated $\mathrm{NaCl}$ solution are decreased with time, whereas the percentage of $\mathrm{NaCl}$ removal is increased. These are presumable results because as desalination proceeds in the diluate compartment and therefore concentration and conductivity of $\mathrm{NaCl}$ are decreased with time, also the current must be decreased, while the solution resistance is increased. Fig. 4 shows the current and conductivity decrease of the treated $\mathrm{NaCl}$ solution versus time while fig. 5 shows the concentration variation and the percent removal versus time of $\mathrm{NaCl}$ in the diluate compartment.

The percent removal is calculated from the formula:

percent removal $=\frac{C_{0}-C}{C_{0}} \times 100$

where $\mathrm{Co}$ and $\mathrm{C}$ are the feed and diluate concentrations respectively. 
Table 1.

Voltage (E) and current (I) measurements inside and outside the ESZ-ICS, with and without electrostatic shielding (ES).

\begin{tabular}{|c|c|c|c|c|c|c|c|c|c|c|c|c|}
\hline $\begin{array}{l}\mathrm{E}_{A-F} \\
(\mathrm{~V})\end{array}$ & $\begin{array}{c}\mathrm{E}_{B-E} \text { without ES } \\
\text { (V) }\end{array}$ & $\begin{array}{l}E_{B-E} \text { withES } \\
\text { (V) }\end{array}$ & $\begin{array}{c}\mathrm{E}_{C-D} \text { without ES } \\
(\mathrm{V})\end{array}$ & $\begin{array}{l}E_{C-D} \text { with } \\
\text { ES (V) }\end{array}$ & $\begin{array}{c}\mathrm{I}_{C-D} \\
\text { without ES } \\
(\mathrm{mA})\end{array}$ & $\begin{array}{c}\mathrm{I}_{C-D} \\
\text { with ES } \\
(\mathrm{mA})\end{array}$ & $\begin{array}{c}\mathrm{E}_{A-B} \text { without ES } \\
(\mathrm{V})\end{array}$ & $\begin{array}{c}E_{A-B} \text { with ES } \\
\text { (V) }\end{array}$ & $\begin{array}{c}\mathrm{E}_{E-F} \text { without ES } \\
\text { (V) }\end{array}$ & $\begin{array}{l}\mathrm{E}_{E-F} \text { with } \\
\text { ES (V) }\end{array}$ & $\begin{array}{c}\mathrm{I}_{\mathrm{s}} \\
\text { without ES } \\
(\mathrm{mA})\end{array}$ & $\begin{array}{lc}I_{s} & \text { with } \\
\text { ES } & (\mathrm{mA})\end{array}$ \\
\hline 4.0 & 1.22 & 0 & 0.41 & 0.05 & 0.62 & 0.03 & 0.40 & 0.92 & 2.31 & 3.01 & 2.53 & 4.42 \\
\hline 5.0 & 1.83 & 0 & 0.60 & 0.06 & 0.72 & 0.04 & 0.65 & 1.42 & 2.50 & 3.52 & 3.74 & 5.93 \\
\hline 6.0 & 2.20 & 0 & 0.64 & 0.07 & 0.84 & 0.05 & 0,82 & 1,79 & 2.98 & 4.14 & 4.56 & 7.25 \\
\hline 8.0 & 3.11 & 0 & 0.98 & 0.08 & 1.57 & 0.07 & 1.25 & 2.70 & 3.65 & 5.12 & 6.84 & 12.92 \\
\hline 10.0 & 4.33 & 0 & 1.41 & 0.09 & 2.26 & 0.08 & 1.61 & 3.63 & 4.11 & 6.20 & 9.36 & 18.84 \\
\hline 12.0 & 5.48 & 0 & 1.82 & 0.09 & 3.22 & 0.09 & 1.82 & 4.62 & 4.70 & 7.33 & 12.25 & 25.44 \\
\hline 14.0 & 6.68 & 0 & 2.19 & 0.10 & 4.30 & 0.10 & 2.20 & 5.54 & 5.12 & 8.41 & 14.80 & 31.52 \\
\hline 18.0 & 8.95 & 0 & 2.95 & 0.10 & 6.14 & 0.10 & 3.16 & 7.66 & 6.14 & 10.72 & 20.10 & 43.45 \\
\hline 21.5 & 10.82 & 0 & 3.51 & 0.10 & 7.63 & 0.10 & 3.91 & 9.33 & 6.78 & 12.18 & 22.95 & 51.66 \\
\hline 25.5 & 13.54 & 0 & 4.48 & 0.11 & 9.52 & 0.10 & 4.74 & 11.40 & 7.36 & 14.13 & 28.23 & 62.63 \\
\hline 30.0 & 15.93 & 0 & 5.28 & 0.11 & 12.45 & 0.11 & 5.24 & 13.65 & 9.05 & 16.35 & 37.36 & 80.44 \\
\hline
\end{tabular}




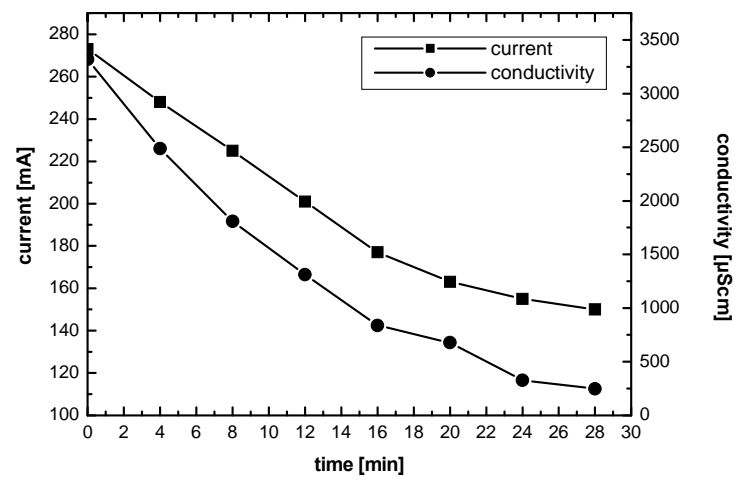

Fig. 4 Current and conductivity measurements of the treated $(0.03 \mathrm{M})$ $\mathrm{NaCl}$ solution in diluate versus time by the electrostatic shielding desalination process

The current density can considerably be enhanced $[44,45]$ by reducing the ICS thickness and simultaneously increasing the applied cell voltage. For this purpose extra thin ICSs are needed, so as not to exceed the electrochemical decomposition potential of water and to avoid the unproductive charge transfer reactions through faradaic currents $I_{f}$ at their polarized sides as illustrated in fig.1a.b,c. Such thin ICS sheets could be constructed by specific chemical vapour deposition on thin perforated metallic sheets [32,33], by the paste rolling method [51] or as described in $[35,36]$.

Because of risk of formation of the aggressive chlorine by eventuall $\mathrm{Cl}^{-}$ion discharging at the anodically polarized sides of the ICS, the potential difference between its two polarized sides should not exceed the value of $1.3 \mathrm{~V}$. If the ICS thickness is reduced from $5 \mathrm{~mm}$ to $0.3 \mathrm{~mm}$ the voltage between its polarized sides is reduced to $1.3 \cdot 0.3 / 5=0.18$ $\mathrm{V}$. Consequently, the current density of $1.82 \mathrm{~mA} \mathrm{~cm}^{-2}$ can be increased to $1.3 / 0.18 \cdot 1.82=13.14 \mathrm{~mA} \mathrm{~cm}^{-2}$ for the used feed water concentration of $1755 \mathrm{mg} \mathrm{L}^{-1} \mathrm{NaCl}$ $(0.03 \mathrm{M})$ while for higher feed solution concentrations the process can be operated with proportionally higher current densities. The current density per $\mathrm{cm}^{2}$ ICS can furthermore be increased by increasing the end-electrode surfaces, so that an increased source current $I_{s}$ can flow through the cell at the same cell voltage. In addition, use of inhibitors or ICS materials with high overpotential to hydrogen and oxygen evolution can prevent the unproductive charge transfer reactions and allow an additional voltage and current density increase.

The applied cell potential was $35 \mathrm{~V}$ of which $3 \mathrm{~V}$ correspond to the total potential drop on the anolyte and catholyte, $2.6 \mathrm{~V}$ on the treated solution in the diluate compartments and $3 \mathrm{~V}$ on the end-electrodes. The electronically and ionically conducting and shorted ICSs, as all electronic conductors, require practically no potential drop to carry the current through their mass. The bulk of the potential $(26.4 \mathrm{~V})$ drops on the diaphragms D used.

Powder bed electrodes can not be used without diaphragms which, however, increase the cell resistance. If our graphite powder bed/diaphragms are replaced with conducting thin porous ceramic composite carbon electrode sheets, carbon papers or carbon aerogels, as already stated, the cell voltage and consequently the energy consumption can considerably be reduced. Furthermore, by using multicell arrangements with alternating concentrate and diluate compartments also the potential drop on the two endelectrodes and the anolyte and catholyte will become negligible. In such multi-cells (100-200 unit cell stack) each unit cell comprises one diluate and one concentrate compartment (ICS), and the voltage drop for each unit cell will be only for electromigration of ions in the diluate compartment. The proposed electrodialytic process can become energy efficient. It seems to be energetically advantageous over the classical capacitive deionization process because of the fact that the intermediate electrodes (ICSs) are short-circuited and the electrical energy is not consumed in forming any potential profile but only for electromigration of ions in the diluate compartments $[44,45]$.

The process can be operated also continuously under a constant flow rate of $1.2 \times 10^{-4} \mathrm{~L} \mathrm{~s}^{-1}$ and a constant concentration of $500 \mathrm{mg} \mathrm{L}^{-1} \mathrm{NaCl}$ in diluate. The treated solution is fed to the electrodialysis cell by gravity flow (fig.2).

It can be seen in fig.2a,b that, except for water desalination, the proposed process could also be used for splitting of $\mathrm{NaCl}$ or other salts and regeneration of the corresponding acids and bases. The generated $\mathrm{H}^{+}$ions in the anode and the $\mathrm{Cl}^{-}$ions from the adjacent diluate compartment are pushed inside the ICS next to anode forming a $\mathrm{HCl}$ concentrate. In the same way, the generated $\mathrm{OH}^{-}$ions in the cathode and the $\mathrm{Na}^{+}$ions from the adjacent diluate compartment are pushed inside the ICS next to cathode forming a $\mathrm{NaOH}$ concentrate. However, we have not investigated yet the efficiency and quality of the obtained acid and base concentrates. This will be an objective of our next studies.

The polarity of the proposed electrodialysis cell can be reversed very easily without any change or rearrangement of the electrodes, the ICSs or the diluate and concentrate compartments. Polarity reversal causes polarization reversal of the ICSs and direction reversal of the migrating ions (fig.2a,b). By alternating the polarity the deionization process is not interrupted, the ICSs are neither alternatively charged/discharged unlike capacitive deionization cells, nor the diluate and concentrate compartments alternate unlike classical electrodialysis or electrodialysis reversal cells with permselective membranes. In the latter cells polarity reversal is operated as quickly as possible and periodically (about once an hour) at costs of the deionization process and only to avoid scaling of membranes [3]. The proposed cell is not at all affected by alternating the polarity and works continuously. The ICSs continue to behave as concentrate compartments and collect ions from both their sides independently from which side anions or cations enter the unchanged concentrating compartments. Polarity reversal requires dimensionally stable electrodes as ICS materials.

The proposed process combines many characteristics of all classical electrodeionization technologies and abolishes the differences between them. It can be regarded as a unified continuous capacitive deionization - continuous electrodeionization - electrodialysis - electrodialysis reversal process [45]. 


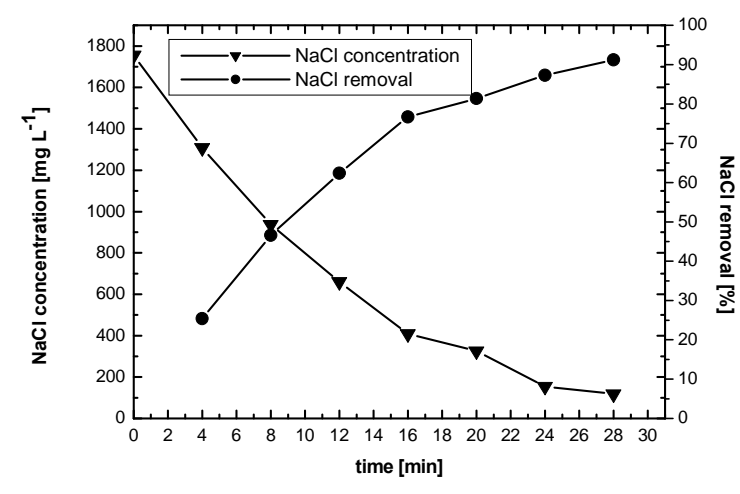

Fig. 5 Concentration variation and removal percent of $\mathrm{NaCl}$ in diluate versus time by the electrostatic shielding desalination process of a 0.03 $\mathrm{M} \mathrm{NaCl}$ solution

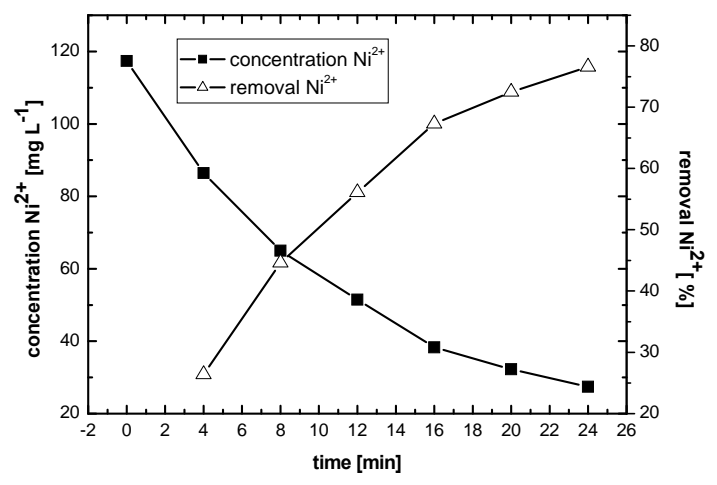

Fig. 6 Concentration variation and percent removal of $\mathrm{Ni}^{2+}$ ions in diluate versus time by the electrostatic shielding electrodialysis process of a $0.002 \mathrm{M} \mathrm{NiSO}_{4}$ solution.

In contrast to the very sensitive to scaling membranes, our porous ICSs are less affected by it and by alternating the polarity become absolutely unaffected. When keeping the cell polarity constant hydrogen evolution occurs at the cathode and partially at the cathodically polarized sides of the ICSs (fig.1b). This involves a local increase of $\mathrm{pH}$ and a precipitation of insoluble hydroxides or carbonates (scaling) which can affect the porosity and thus the ionic conductivity of the ICSs. Hydrogen evolution via electrochemical water decomposition and therefore scaling at the cathodically polarized sides of the ICSs can be overcome, as pointed out before by using thin ICS-materials with high overpotential to hydrogen and oxygen in order not to exceed the electrochemical decomposition potential of water. Furthermore, scaling is avoided by suitably pretreating water via chemical precipitation or ion exchange to remove scalant ions e.g. $\mathrm{Ca}^{2+}, \mathrm{Mg}^{2+}$. As stated in the introductory section, concentration polarization and depleted boundary layers at the interfaces solution-ICS and ICS-solution are not observed and, unlike ion exchange membranes, water dissociation at these interfaces can practically not occur. The water dissociation potential is $0.83 \mathrm{~V}$ [19] but water dissociation is insufficient even at larger voltage when the concentration polarization is weak $[22,23]$.Therefore, scaling related to water dissociation, $\mathrm{H}^{+}$ion electromigration and $\mathrm{pH}$ increase at the cathodically polarized sides of the ICSs is minimal.
In a more convenient way, scaling can be completely overcome if the polarity of the cell alternates. Since in our cell, polarity reversal does not involve any process interruption or conversion of diluate to concentrate compartment and vice versa, it can be operated continuously. Furthermore, alternating the polarity entails alternating hydrogen and oxygen evolution due to electrochemical water decomposition and alternating $\mathrm{H}^{+}$and $\mathrm{OH}^{-}$ion electromigration due to water dissociation at the same polarized side of each ICS. In this way $\mathrm{pH}$ remains constant in all cell compartments and the possibility of formation of the undesirable insoluble hydroxide or carbonate precipitates is completely excluded. Consequently scaling does not appear at all and any preliminary water treatment is practically not needed.

\subsection{Removal of heavy metals - electrostatic shielding electrodialysis of a $0.002 \mathrm{M} \mathrm{NiSO}_{4}$ solution.}

Industrial effluents originating mainly from electroplating industries contain heavy metal ions $\left(\mathrm{Cr}^{6+}, \mathrm{Ni}^{2+}, \mathrm{Cu}^{2+}, \mathrm{Cd}^{2+}\right.$, $\mathrm{Zn}^{2+}$ ) which are of considerable concern because they are non-biodegradable, highly toxic and probably carcinogen. From the viewpoint of environmental protection and resource saving, effective recycling and reusing of the metal wastewater is strongly expected. Among techniques as chemical precipitation and ion exchange, two electrochemical methods are used to contribute to the solution of this serious environmental problem e.g. electrodialysis [52] and electrodeionization with simultaneously water recovery for reuse) [4,5,9-13].

The proposed new electrostatic shielding electrodialysis cell with ICSs instead of ion exchange membranes has proved to be efficient also for the removal of heavy metal ions such as $\mathrm{Ni}^{2+}$. We have treated a $0.002 \mathrm{M} \mathrm{NiSO}_{4}$ solution $\left(117.4 \mathrm{mg} \mathrm{L}^{-1} \mathrm{Ni}\right)$ which was placed in the diluate and the electrode compartments of the cell illustrated in fig.2. The obtained experimental results are listed in table 3.

\section{Table 3.}

Electrostatic shielding electrodialysis of a $0.002 \mathrm{M} \mathrm{NiSO}_{4}$ solution.

\begin{tabular}{cccc}
\hline $\begin{array}{c}\text { Time } \\
(\mathrm{min} .)\end{array}$ & $\begin{array}{c}\text { Current } \\
(\mathrm{mA})\end{array}$ & $\begin{array}{c}\text { Concentration } \\
\mathrm{Ni}^{2+}\left(\mathrm{mg} \mathrm{L}^{-1}\right)\end{array}$ & $\begin{array}{c}\text { Removal } \mathrm{Ni}^{2+} \\
(\%)\end{array}$ \\
\hline 0 & 135 & 117.4 & - \\
4 & 108 & 86.4 & 26.4 \\
8 & 97 & 65.0 & 44.6 \\
12 & 92 & 51.5 & 56.1 \\
16 & 88 & 38.3 & 67.3 \\
20 & 86 & 32.2 & 72.5 \\
24 & 85 & 27.4 & 76.6 \\
\hline
\end{tabular}

Fig.6 Depicts the concentration variation of $\mathrm{Ni}^{2+}$ ions in diluate versus time.

The process was conducted under same conditions as the electrodialysis desalination process described before i.e. under constant voltage and decreasing current. $\mathrm{Ni}^{2+}$ cations in the diluate and the anodic compartments permeate the 
ICSs and accumulate there. At higher fields where the decomposition potential of $\mathrm{NiSO}_{4}$ can be exceeded, $\mathrm{Ni}^{2+}$ ions can also partially be electronated and electrodeposited to pure metal at the cathodically polarized sides of the ICSs through charge transfer reactions as demonstrated in fig. $1 \mathrm{~b}$. Both phenomena contribute to nickel removal in the diluate and the anodic compartments. Furthermore, $\mathrm{Ni}^{2+}$ ions are electrodeposited at the cathode in the cathodic compartment. Consequently, nickel removal occurs simultaneously in all cell compartments. The $\mathrm{Ni}^{2+}$ ion concentrate received from the bottom of each ICS may either be recycled to the cathodic compartment to be electrodeposited as pure metal through electrowinning or be given back to the electrolytic cobalt bath for reuse. The produced pure water can be reused as rinsing water. In this way, the process can save a lot of water resource and realize "zero pollution". The removal of $\mathrm{Ni}^{2+}$ ions is more effective when the electrodialysis cell is assisted by ion exchange resins as will be explained below.

\subsection{Electrostatic shielding regeneration of ion exchange resins -electrodeionization of a $0.001 \mathrm{M} \mathrm{NiSO}_{4}$ solution.}

High purity deionized water can be produced with the filled cell electrodeionization device (fig.2), if separated beds of cation exchange resins (CR) and anion exchange resins (AR) are placed in the diluate compartment. Feed water permeates simultaneously the separated beds of $\mathrm{CR}$ and $\mathrm{AR}$ resins in the diluate compartment, while a concentrate is formed at the bottom of each ICS. Although CR and AR resins are separated, feed water does not need to permeate first the CR and then the AR resin, because, due to the electric field, the moving cations and anions reach simultaneously, both, CR and AR resins and therefore are simultaneously exchanged [44].

If the EDI cell with only one ICS is used as it is illustrated in fig. 3 the separated bed resins CR and AR are placed in the anodic and cathodic compartment respectively. Feed water must permeate first the $\mathrm{CR}$ and then the $\mathrm{AR}$ resin to be deionized.

We used a synthetic $0.001 \mathrm{M} \mathrm{NiSO}_{4}$ solution $\left(58.7 \mathrm{mg} \mathrm{L}^{-}\right.$ ${ }^{1} \mathrm{Ni}$ ) and obtained pure water with a $\mathrm{Ni}^{2+}$ ion concentration of less than $0.5 \mathrm{mg} \mathrm{L}^{-1}$ in both modes, batch or continuous, while the resins are simultaneously regenerated without the use of any chemical regenerants (fig.3). The product water quality stays constant overtime, whereas in regenerable ion exchange with chemicals it degrades as the resins approach exhaustion. In the continuous mode with a flow rate of $2.3 \times 10^{-4} \mathrm{~L} \mathrm{~s}^{-1}$ diluate stream the current efficiency for $\mathrm{Ni}^{2+}$ ion removal is $28 \%$.

$\mathrm{H}^{+}$and $\mathrm{OH}^{-}$ions are formed at the anode and cathode through the water splitting reactions:

$$
\begin{aligned}
& \mathrm{H}_{2} \mathrm{O} \rightarrow 2 \mathrm{H}^{+}+1 / 2 \mathrm{O}_{2}+2 \mathrm{e} \quad \text { (anode) } \\
& 2 \mathrm{H}_{2} \mathrm{O}+2 \mathrm{e} \longrightarrow 2 \mathrm{OH}^{-}+\mathrm{H}_{2} \text { (cathode) }
\end{aligned}
$$

The generated $\mathrm{H}^{+}$ions in the anode compartment repel and replace the $\mathrm{Ni}^{2+}$ cations from the $\mathrm{CR}$ resin and the generated $\mathrm{OH}^{-}$ions in the cathode repel and replace the anions from the $\mathrm{AR}$ resin. The replaced cations $\left(\mathrm{Ni}^{2+}\right)$ and anions $\left(\mathrm{SO}_{4}{ }^{2-}\right)$ together with the electroosmotically transported water molecules are transferred to the ICS where they accumulate and can be received as a concentrate from its bottom.

Partial precipitation of insoluble hydroxides (scaling) such as $\mathrm{Ni}(\mathrm{OH})_{2}$ is locally observed inside the ICS or at its left cathodically polarized boundary where the metal cations and the $\mathrm{OH}^{-}$anions can meet. No precipitation on the CR particles in the anode compartment was observed because this compartment is acidic. The local precipitation of hydroxides inside the ICS and its left boundary can easily be prevented by intermittently rinsing the ICS with a diluted acidic solution $\left(\mathrm{H}_{2} \mathrm{SO}_{4}\right)$.

In case the separated bed $\mathrm{CR}$ and $\mathrm{AR}$ resins are placed inside the central diluate compartment of fig. 2 as described in [44] precipitation of hydroxides can occur at the interface $\mathrm{CR} / \mathrm{AR}$. In this case polarity reversal or rinsing with deionized water and no acidic rinsing is allowed in order not to damage the AR resin. Similar problems of metal hydroxide precipitation on the CR/AR bed interfaces are encountered in classical membrane electrodeionization cells. The resins are placed as layered beds in the diluate compartments to achieve constant $\mathrm{pH}$ and avoid hydroxide precipitation [53].

In ion exchange resin assisted electrodeionization cells the current efficiency is lower than in electrodialysis cells without resins because the current is carried mainly by the faster $\mathrm{H}^{+}$and $\mathrm{OH}^{-}$ions which are formed during the electrodeionization process due to water dissociation. The heavy metal ions, because of greater affinity, adhere to the resin particles and migrate more slowly.

At higher current densities the removal of $\mathrm{Ni}^{2+}$ ions and therefore the current efficiency can be further increased. However, this additional increase is attributed to electrodeposition of the pure metal at the cathodically polarized side of the ICS, due to exceeding the electrochemical decomposition potential of $\mathrm{NiSO}_{4}$ between the two polarized sides of the ICS.

\section{Conclusions}

The proposed new cells with electrostatically shielded zones-ionic current sinks instead of permeselective ion exchange membranes can find several electrochemicaltechnological applications of antipollution. The proposed processes seem promising and advantageous in many aspects over the existing classical technologies. They need further investigation to be developed into innovative and competitive electrochemical processes for brackish or seawater desalination and electrodeionization of heavy metal bearing industrial effluents.

Especially in water desalination and electrodialysis applications, the thick, self-made and energy consuming graphite powder beds/diaphragms which are used as electrostatically shielded zones-ion current sinks should be replaced with thinner porous composite ceramic or polymeric intermediate electrode sheets, carbon papers or carbon aerogels to substantially increase the current density and desalting rate and simultaneously lower the electrical energy consumption. Furthermore, multi-cells with alternating thin diluate and concentrate compartments should be constructed in order to minimize the share of the voltage drop on the two end-electrodes so that the applied cell voltage and the electrical energy is used effectively and almost exclusively for electromigration of ions in the diluate compartments.

Research is needed to gain more information about the implementation possibilities of the proposed ionic current sinks and their dynamics to contribute to the solution of environmental or other technological tasks. 


\section{References}

1. Heiner Strathmann und Horst Chmiel, Chem.-Ing.-Tech., 56, 214 (1984).

2. O. Kedem, J. Membr. Sci., 206, 333 (2002).

3. Ramon Valerdi-Perez and Jose A. Ibanez-Mengual, Desalination, 141, 23 (2001).

4. K.H. Yeon, J.H. Seong, S. Rengaraj, S.H. Moon, Sep. Sci. Technol., 38, 443 (2003).

5. M.J. Semmens, C.D. Dillon, C. Rilley, Environ. Prog., 20, 251 (2001).

6. Hong-Joo Lee, F. Safert, H. Strathmann, Seung-Hyeon Moon, Desalination, 142-267 (2002).

7. H. J. Lee, S.J. Oh, S.H. Moon, Water res., 37, 1091 (2003).

8. K.H. Yeon, J.H. Song, S.H. Moon, Water res., 38, 1911 (2004).

9. L. Sifuentes, R. Glasner and J.M. Casas, Chem. Eng. Sci. 2004, 59, 1087.

10. L. Koene and L.J.J. Janssen, Electrochim. Acta , 47, 695 (2001).

11. P.T. Bolger and D.C. Szlag, Environ. Prog., 21, 203 (2002).

12. P.B. Spoor, W.R. ter Veen and L.J.J. Janssen, J.Appl. Electroch., , 31, 523 (2001).

13. Y.S. Dzyazko, Desalination, 198, 47 (2006)

14. H. Strathmann, J. J. Krol, H.-J. Rapp and Eigenberger, J. Membr. Sci., 125, 123 (1997).

15. G. Khedr, A. Schmitt and R. Varoqui, J. Colloid Interface Sci., 66, 516 (1978).

16. M. Taky, G. Pourcelly and C. Gavach, J. Electroanal. Chem., 336, 195 (1992).

17. P. Sistat and G. Pourcelly, J. Electroanal. Chem., 460, 53 (1999).

18. Yoshinobu Tanaka, J. Membr. Sci., , 244, 1 (2004).

19. R. Simons, Electrochim. Acta , 29, 151 (1984).

20. I. Rubinstein, E. Staude and O. Kedem, Desalination, 69, 101 (1988).

21. I. Rubinstein and B. Zaltzman, Phys. Rev. E , 62, 2238 (2000).

22. N.A. Mishchuk, Colloids Surf. A, , 140, 75 (1998).

23. N.A. Mishchuk, L.K. Koopal, Colloids Surf. A, , 176, 195 (2001).

24. J.C. Farmer, D.V. Fix, G.V. Mack, R.W. Pekala and J.F. Poco, J. Appl. Electroch., , 26, 1007 (1996).

25. C.J. Gabelich, T.D. Tran and I.H. Mel Suffet, Environ. Sci. Technol., , 36, 3010 (2002).

26. T.J. Welgemoed, C.F. Schutte, Desalination, 183, 327 (2005).

27. L. Zhang, Z. Cao, P. Chen, Z.-D. Cui, Z.-Y. Sheng, F. Xu, L.-X Sun, Congneng Cailiao J. Functional Mater., 39,1727 (2008).

28. Pei Xu, Joerg E. Drewes, Dean Heil, Gary Wang, Water Res., 42, 2605 (2008).

29. Hong-Joo Ahn, Jong-Ho Lee, Yongsoo Jeong, Jun-Hee Lee, Choong-Soo Chi, Han-Jun Oh, Mater. Sci. Eng., A 449-451, 841 (2007).
30. Hae-Hyun Jung, Sung-Woo Hwang, Sang-Hoon Hyun, Kang-Ho Lee, Gye-Tai Kim, Desalination, 216, 377 (2007).

31. Sung-Woo Hwang, Sang-Hoon Hyun, J. Non-Cryst. Solids, 347, 238 (2004).

32. Wendy S. Baker, Jeffrey W. Long, Rhonda M. Stroud and Debra R. Rolison, J. Non-Cryst. Solids, 350, 80 (2004).

33. X. Z. Wang, M. G. Li, Y. W. Chen, R.M. Cheng, S.M. Huang, L.K. Pan and Z.Sun, Appl. Phys. Lett., 89, 053127 (2006).

34. Beom-Jin Yoon, Soo-Hwan Jeong, Kun-Hon Lee, Hyung Seok Kim, Chan Gyung Park, Jong Hun Han, Chem. Phys. Lett., 388, 170 (2004).

35. X. Z. Wang, M. G. Li, Y. W. Chen, R.M. Cheng, S.M. Huang, L.K. Pan and ZSun, Electrochem. Solid-State Lett., 9, E23-E26 (2006).

36. Wang Shuo, Wang Dazhi, Ji LiJun, Gong Qianming, Zhu YueFeng, Liang Ji, Sep. Purif. Technol., 58, 12 (2007).

37. Min-Woong Ryoo and Gon Seo, Water Res., 37, 1527 (2003)

38. Min-Woong Ryoo, Jong-Ho Kim and Gon Seo, J. Colloid Interface Sci., 264,414 (2003).

39. Han-Jun Oh, Jong-Ho Lee, Hong-Joo Ahn, Yongsoo Jeong, Young-Jig Kim, Choong-Soo Chi, Thin Solid Films, , 515, 220 (2006).

40. B.H. Yao, D. Lian, J. Wu, D., Biomedical Engineering, IEEE Transactions on, 49, 277, (2002)

41. US Patent 5339019 (1994)

42. European Patent EP1840693 (2003)

43. K. Dermentzis, Greek Patent GR1004819 (2005)

44. K. Dermentzis, Electrochim. Acta, 53, 2953 (2008).

45. K. Dermentzis, K.Ouzounis, Electrochim. Acta, 53, 7123 (2008).

46. M. Baertsch, A. Braun, B. Schnyder, R. Koetz, O. Haas, J. New Mat. Electroch. Syst., 2, 273 (1999).

47. H.D. Young, R.A. Freedman, University Physics, ninth edition, Addison Wesley,p. 721 (1996).

48. N.A. Mischuk, S. Barany, A.A. Tarovsky, F. Madai, Colloid. Surf. A, 140,43 (1998).

49. N.A. Mischuk, Colloid. Surf. A, 159, 467 (1999).

50. T. Mohammadi, A. Moheb, M. Sadrzadeh, A. Razmi, Desalination, 169, 21 (2004).

51. Chun-Mo Yang, Woon-Hyuk Choi, Byung-Ki Na, Byung Won Cho, Won Il Cho, Desalination, 174, 125 (2005).

52. L. Marder, A.M. Bernandes, J. Z. Ferreira, Sep. Purif. Technol., 37, 247 (2004).

53. Kyeong-Ho Yeon, Jung-Hoon Song, Seung-Hyeon Moon, Water res., 38, 1911 (2004). 